\section{Characterization of non-typhoidal Salmonella enterica strains of human origin in central and southern Italy}

\author{
Yolande T.R. Proroga, ${ }^{1}$ \\ Federico Capuano, \\ Rosanna Capparelli, ${ }^{2}$ Stefano Bilei, ${ }^{3}$ \\ Mariano Bernardo, ${ }^{4}$ Maria Pia Cocco, \\ Rosalba Campagnuolo, ${ }^{6}$ \\ Vincenzo Pasquale ${ }^{7}$
}

${ }^{1}$ Department of Food Microbiology, Regional Laboratory for Salmonella Serotyping, Institute for Experimental Veterinary Medicine of Southern Italy, Portici; ${ }^{2}$ Department of Agriculture, University of Naples Federico II, Portici; ${ }^{3}$ Department of Food Microbiology, Institute for Experimental Veterinary Medicine of the Lazio and Tuscany Regions M. Aleandri, Rome; ${ }^{4}$ Microbiology and Virology Laboratory, Specialist Hospital Monaldi-CotugnoCTO, Naples; ${ }^{5}$ Laboratory of Clinical Pathology, Local Health Unit Naples 2 North, Pozzuoli; ${ }^{6}$ Laboratory of Clinical Pathology and Microbiology, A.O.R.N. Santobono-Pausilipon, Naples; ${ }^{7}$ Department of Science and Technology, University of Naples Parthenope, Naples, Italy

\begin{abstract}
Non-typhoidal Salmonella enterica infection is a significant public health problem worldwide. The aim of this study was to characterize Salmonella enterica strains isolated from human specimens in central and southern Italy, for epidemiological studies. One hundred and fifty $S$. enterica strains were serotyped. Isolates were tested for their antimicrobial susceptibility, by disk diffusion method. The molecular characterizations, based on PCR, were carried out for the detection of invA gene and other virulence elements and phage marker genes. Eighteen different Salmonella serotypes were identified. The most common serotypes detected were $S$. Typhimurium, $S$. Enteritidis, the monophasic variant of $S$. Typhimurium ( $S$. 4,[5],12:i:-), and $S$. Napoli. High resistance rates were recorded for tetracycline $(64 \%)$, streptomycin $(62 \%)$, sulphonamide (57\%), and ampicillin (56\%). The ASSuT R-type, also associated to resistance to other antibiotics, was highly prevalent in $S$. 4,[5],12:i:- $(97 \%)$ and $S$. Typhimurium (55\%), while the ACSSuT R-
\end{abstract}

type, also associated to other antibiotics, was observed prevalently in $S$. Typhimurium $(20.4 \%)$. The genes of more common detection were invA (100\%), sspH2 (86.6\%), gtgB (84.6\%), g8 (80\%), sodC1 $(77.3 \%)$, gipA $(52.6 \%)$, sspH1 $(52.6 \%)$.

\section{Introduction}

Non-typhoid serovars of Salmonella enterica subspecies enterica and Campylobacter spp. are the most common etiological agents of bacterial food-borne diseases in Europe (EFSA and ECDC, 2016). Recently, Havelaar et al. (2012) estimated that approximately 6.2 million cases of human salmonellosis occur in the EU member states each year. The incidence rates of Salmonella infections are generally elaborated from culture-confirmed cases, which constitute only a small fraction of all cases occurring in a community (Mellou et al., 2013).

Even though over 2500 different serotypes of $S$. enterica are reported to date (Popoff and Le Minor, 2005), most human infections are caused by few serotypes. $S$. Enteritidis and $S$. Typhimurium are among the serovars most frequently associated with human food-borne diseases in the EU, accounting for up to $68 \%$ of confirmed human cases identified at the serotype level (Graziani et al., 2013). Poultry and poultry products, particularly eggs, have been identified as the main source of human $S$. Enteritidis infections, whereas human $S$. Typhimurium infections mainly originated from pigs (Pires et al., 2011). In the last two decades, detection of $S$. Typhimurium and $S$. Typhimurium monophasic variant $(S$. 4,[5],12:i-) characterized by antimicrobial resistance to Ampicillin (A), Streptomycin (S), Sulphonamide (Su), Tetracycline (T) (R-type ASSuT) and Chloramphenicol (C) (R-type ACSSuT) increased significantly in many countries (Capuano et al., 2013; Lucarelli et al., 2010).

The main epidemiological surveillance tools of salmonellosis carried out in the national reference laboratories remain the serotyping of isolates and the evaluation of their antibiotic resistance. Further and complementary data can be acquired from DNA fingerprinting, phage-typing and other molecular biology-based assays for Salmonella (Abatcha et al., 2014).

In addition, serotype and antibiotic resistance of Salmonella strains are carried out by the use of well standardized techniques, whereas the evaluation of virulence markers is not standardized and universally accepted, though many assays have been
Correspondence: Federico Capuano, Istituto Zooprofilattico, Via Salure 2, 80055 Portici (NA), Italy.

Tel.: +39.081.7865117

E-mail: federico.capuano@cert.izsmportici.it

Key words: Salmonella enterica, human isolates, antibiotic resistance, R-type ASSuT, Rtype ACSSuT, virulotype.

Acknowledgments: The authors would like to thank Prof. Stefano Dumontet for his valuable suggestions.

Contributions: the authors contributed equally

Conflict of interest: the authors declare no potential con conflict of interests.

Funding: none

Received for publication: 7 July 2017

Revision received: 6 October 2017.

Accepted for publication: 9 October 2017

This work is licensed under a Creative Commons Attribution-NonCommercial 4.0 International License (CC BY-NC 4.0).

CC Copyright Y.T.R. Proroga et al., 2018

Licensee PAGEPress, Italy

Italian Journal of Food Safety 2018; 7:6888 doi:10.4081/ijfs.2018.6888

developed over the years (Huehn et al., 2010).

The aim of this study was to investigate serotype, antimicrobial susceptibility and virulotype of clinical non-typhoidal $S$. enterica strains, isolated from human samples in central and southern Italy.

\section{Materials and Methods}

One hundred and fifty Salmonelle enterica strains of human origin were collected from January 2013 to December 2015 by the Centro Tipizzazione Salmonelle, the public reference laboratory for Salmonella characterization, from hospitals located in Campania and Lazio regions (southern and central Italy). The isolates were serotyped and the antimicrobial susceptibility was performed on all isolates as below described; furthermore all Salmonella strains were molecularly characterized. All strains were isolated from hospitalized patients, whose ages ranged from 3 months to 81 years. In particular, 58 strains were isolated from children aged less than 5 years, 37 from patients aged between 5 and 15 year and 55 strains were isolated from adults. One hundred forty nine strains were isolated from stool sam- 
ples, whereas 1 strain was isolated from lymphoid tissue (popliteal lymph node).

Isolates were serotyped by agglutination with specific sera (Statens Serum Institute, DK and Difco, NJ, USA) to identify variants of the somatic $(\mathrm{O})$ and flagellar $(\mathrm{H})$ antigens, according to WhiteKauffmann-Le Minor scheme (Grimont and Weill, 2007; Popoff and Le Minor 2005).

\section{Molecular identification of S. enteri- ca serotype 4,[5],12:i:-}

The serological identification of $S$. enterica serotype 4,[5],12:i:- specific was confirmed by molecular targets amplified as previous described (Capuano et al., 2013).

The antibiotic susceptibility of the isolates was studied by Kirby-Bauer disk diffusion method according to the Clinical and Laboratory Standards Institute recommendations (CLSI 2008). Eleven different antimicrobial categories were tested: penicillins (ampicillin, $10 \mu \mathrm{g}$ ), penicillins $+\mathrm{b}$ lactamase inihibitors (amoxicillin-clavulanic acid, $30 \mu \mathrm{g}$ ), non-extended ( $1^{\text {st }}$ generation) spectrum cephalosporins (cephalothin, $30 \mu \mathrm{g})$, extended-spectrum ( $3^{\text {rd }}$ generation) cephalosporins (cefotaxime, $30 \mu \mathrm{g}$; ceftazidime, $30 \mu \mathrm{g}$ ), phenicols (chloramphenicol, $30 \mu \mathrm{g}$ ), polymyxins (colistinsulphate, $10 \mu \mathrm{g}$ ), quinolones (nalidixic acid, $30 \mu \mathrm{g}$; ciprofloxacin, $5 \mu \mathrm{g}$; enrofloxacin, $10 \mu \mathrm{g}$ ), aminoglycosides (gentamicin, $10 \mu \mathrm{g}$; kanamycin, $30 \mu \mathrm{g}$; streptomycin, $10 \mu \mathrm{g}$ ), sulphonamides (sulphonamide, $300 \mu \mathrm{g}$ ), tetracyclines (tetracycline, $30 \mu \mathrm{g}$ ), and folate pathway inhibitors (trimethoprimsulfamethoxazole, $25 \mu \mathrm{g}$ ). Escherichia coli ATCC 29213 was used as a quality control. Strains showing non-susceptibility to at least 1 antibiotic in 3 or more antimicrobial categories was defined as multidrug resistant (MDR) (Magiorakos et al., 2012).

In relation to virulotyping analysis, the isolates were analysed for the presence of 14 virulence genes: invA, spvC (Chiu and Ou, 1996), nanH, gip $A, \operatorname{gtg} B$ (Mikasovà et al., 2005), sodC1, mig5, $\operatorname{srg} A$, sspH1, sspH2, rck (Borriello et al., 2012), pefA (Heithoff et al., 2008), sopE (Drahovska et al., 2007) and grvA (Ho and Slauch, 2001), by singleplex, duplex or triplex PCR assays.

All Salmonella isolates were examined for the presence of 4 gene markers of the phage P22 not related to Salmonella virulence: $e a E$ (encoding for the Eae protein), $g 8$ (encoding for the phage scaffold protein), $g 13$ (encoding for holin) and sieB (encoding for the superinfection exclusion system) (Mikasova et al., 2005).

All molecular assays were carried out in a reaction volume of $25 \mu \mathrm{L}$, employing $2 \mu \mathrm{L}$ DNA template extracted from single Salmonella colonies through thermal cell lysis. Post-PCR detection of the amplicons was carried out by electrophoresis in agarose gel (1.5\%) stained with SYBR-Safe (Life Technologies, Foster City, CA, USA).

Statistically significant differences in both the antibiotic resistance and virulotypes of the isolates were evaluated by the EpiInfo 7 software (Centers for Disease Control and Prevention, Atlanta, USA). A two-tailed chi-squared test $\left(\mathrm{X}^{2}\right)$ was used to evaluate differences between proportions among the different stratification groups; variables with a value of $\mathrm{P}<0.05$ were considered statistically significant. The strength of the associations between data was quantified by computing the Odds Ratios (OR); OR values $>1$, considering a $95 \%$ confidence interval, were accepted as significant.

\section{Results}

\section{Serotyping}

The $150 \mathrm{~S}$. enterica strains studied belonged to 18 serotypes (Table 1); the most common were: $S$. Typhimurium (49/150), $S$. Enteritidis (40/150), S. 4,[5],12:i:(37/150), and $S$. Napoli (7/150). These four serotypes accounted for $88.6 \%$ of all isolates. Other less frequent Salmonella serotypes were Derby, Poona, Rissen $(2 / 150,1.3 \%)$, and Agama, Blockley, Brandenburg, Bredeney, Edinburgh, Hadar, Irumu, Manhattan, Muenster, Nyborg, Ohio $(1 / 150,0.7 \%)$.

\section{Antibiotic resistance}

Thirty-nine isolates $(26.0 \%)$ out of 150 were susceptible to all antibiotics tested, whereas $12(8.0 \%), 7(4.6 \%)$ and $5(3.3 \%)$ isolates were resistant to 1,2 and 3 antibiotics, respectively. Interestingly, 86 isolates $(57.3 \%)$ were resistant to 4 or more antibiotics, whereas $90 / 150(60.0 \%)$ isolates were considered as MDR (Table 1). No strains

Table 1. Antimicrobial susceptibility patterns (ASSuT, ACSSuT, MDR and XDR) in Salmonella enterica strains.

\begin{tabular}{|c|c|c|c|c|c|c|c|}
\hline Serotype & №. (\%) & Pan susceptible & MDR & ASSuT & ASSuT+others & ACSSuT & ACSSuT+others \\
\hline Typhimurium & $49(32.7)$ & 3 & 42 & 7 & 20 & 1 & 9 \\
\hline Enteritidis & 40 (26.7) & 31 & 2 & 0 & 0 & 0 & 0 \\
\hline $4,[5], 12: \mathrm{i}: 0$ & 37 (24.7) & 0 & 37 & 31 & 5 & 0 & 1 \\
\hline Napoli & $7(4.7)$ & 3 & 0 & 0 & 0 & 0 & 0 \\
\hline Derby & $2(1.3)$ & 1 & 0 & 0 & 0 & 0 & 0 \\
\hline Poona & $2(1.3)$ & 1 & 0 & 0 & 0 & 0 & 0 \\
\hline Rissen & $2(1.3)$ & 0 & 0 & 0 & 0 & 0 & 0 \\
\hline Agama & $1(0.7)$ & 0 & 1 & 0 & 0 & 0 & 0 \\
\hline Blockley & $1(0.7)$ & 0 & 1 & 0 & 0 & 0 & 0 \\
\hline Brandenburg & $1(0.7)$ & 0 & 1 & 0 & 0 & 0 & 0 \\
\hline Bredeney & $1(0.7)$ & 0 & 1 & 0 & 0 & 0 & 1 \\
\hline Edinburgh & $1(0.7)$ & 0 & 1 & 0 & 0 & 0 & 0 \\
\hline Hadar & $1(0.7)$ & 0 & 1 & 0 & 0 & 0 & 0 \\
\hline Irumu & $1(0.7)$ & 0 & 1 & 0 & 1 & 0 & 0 \\
\hline Manhattan & $1(0.7)$ & 0 & 1 & 0 & 0 & 0 & 0 \\
\hline Muenster & $1(0.7)$ & 0 & 1 & 0 & 0 & 0 & 0 \\
\hline Nyborg & $1(0.7)$ & 0 & 0 & 0 & 0 & 0 & 0 \\
\hline Ohio & $1(0.7)$ & 0 & 0 & 0 & 0 & 0 & 1 \\
\hline
\end{tabular}

Su: Sulphonamide; T: Tetracycline; S: Streptomycin; A: Ampicillin; C: Chloramphenicol; MDR: non-susceptibility to at least one agent in three or more antimicrobial categories. 
showing non-susceptibility to all the antibiotics tested were found.

The majority of the isolates was resistant to tetracycline $(64.0 \%)$, streptomycin $(62.0 \%)$, sulphonamide $(57.3 \%)$, and ampicillin $(56.0 \%)$. Lower resistance rates were observed for nalidixic acid $(23.3 \%)$, chloramphenicol (13.3\%), amoxicillin-clavulanic acid (10.7\%), trimethoprim-sulfametoxazole $(8.0 \%)$, cephalothin $(7.3 \%)$, enrofloxacin $(2.7 \%)$, ceftazidime $(2.0 \%)$, gentamcin $(2.0 \%)$, ciprofloxacin $(1.3 \%)$, colistin sulphate $(1.3 \%)$, and cefotaxime $(0.7 \%)$.

Table 2 show the clustering of the Salmonella isolates in 48 resistance patterns (R-type); sixty four strains showed the ASSuT R-type (38 ASSuT and 26 ASSuT plus other resistances) and 13 the ACSSuT R-type (1 ACSSuT and 12 ACSSuT plus other resistances).

The R-type ASSuT, frequently associated with the resistance to other antibiotics, was the most commonly detected profile (42.6\%); in particular, the R-type ASSuT was observed in 63 out of the $86 S$. Typhimurium and $S$. 4,[5],12:1:- isolates. Overall, the R-type ASSuT was commonly associated with resistance to nalidixic acid (23 isolates), rather than chloramphenicol (12 isolates).

Concerning the four Salmonella serotypes most commonly detected, $S$. Typhimurium showed 25 different R-types, $S$. Enteritidis 10, S. 4,[5],12:i:- 5, and $S$. Napoli 4, respectively.

Thirty-six out of the 37 S. 4,[5],12:i:and 27 out of $49 S$. Typhimurium strains showed the R-type ASSuT, in some cases associated to resistance to other antibiotics (Table 1).

\section{Molecular characterization}

Table 3 reports the prevalence of virulence and phage marker genes in Salmonella strains found in the considered isolates, gene prevalence ranged from $0.66 \%$ to $100 \%$.

Fifty six different virulence gene profiles were observed. The highly specific Salmonella gene marker invA was detected in all isolates, it was used as a confirmatory test of Salmonella detection. The virulence genes of bacteriophage origin sspH2 (86.7\%), gtgB (84.7\%), sodC1 (77.3\%), gipA $(60.0 \%)$, and sspH1 $(52.7 \%)$, were also frequently detected (Table 3 ).

In Table 3 the plasmidic virulence genes found in our isolates are reported; the prevalence of these genes ranged from $4.7 \%$ to $34.0 \%: \operatorname{srg} A(34.0 \%)$, rck $(30.7 \%)$, mig5 $(30.0 \%)$, pefA $(22.7 \%)$, and $s p v C(4.7 \%)$. Plasmidic virulence genes were not found in Salmonella serotypes Napoli and 4,[5],12:i:-.

A high variability was observed in the occurrence of specific virulence genes. Among the 56 virulotypes detected we found two predominant profiles (Table 4): 36 invA, gipA, gtgB, sspH1, sspH2, sodC1 (19 S. 4,[5],12:i:- and $17 S$. Typhimurium) and $21 \operatorname{inv} A, \operatorname{gtg} B, \operatorname{sop} E, \operatorname{sspH} 2, \operatorname{sodC1}$, pefA, mig5, rck, $\operatorname{srg} A$ (all $S$. Enteritidis).

The most commonly detected phage markers were $g 8(80.0 \%)$, sieB $(17.3 \%)$, and $g 13(12.0 \%$ ) (Table 3). Eleven different phage marker profiles were identified. The majority of the strains $(57.3 \%)$ were positive for $g 13$ gene only: 31 4,[5],12:i:-, $27 \mathrm{~S}$. Enteritidis, $25 S$. Typhimurium, $1 S$. Brandenburg, $1 S$. Bredeney, and $1 S$. Hadar.

Interestingly, all isolates $S$. Napoli was characterized by the absence of $g 8$ phage markers.

\section{Discussion}

\section{Serotyping}

In agreement with other authors (EFSA, 2016; Graziani et al., 2013), this study showed that $S$. Typhimurium $(32.7 \%$, 49/150), $S$. Enteritidis $(26.7 \%, 40 / 150)$ and S. 4,[5],12:i:- $(24.7 \%, 37 / 150)$ were the most common serotypes responsible for human salmonellosis in Campania and Lazio regions (Table 1).

The frequent detection of $S$. Napoli (4.7\%), although less common than $S$. Typhimurium, $S$. Enteritidis and $S$. 4,[5],12:i:- serotypes, is of some interest owing to its increasing relevance as human pathogen in Europe. Graziani et al. (2013) reported that in Italy, France and Switzerland from 2000 to 2011, the detection of $S$. Enteritidis and $S$. Infantis decreased significantly, S. Typhimurium remained stable, while other serotypes, including $S$. 4,[5],12:i:- and $S$. Napoli increased significantly. $S$. Napoli, however, is rarely isolated from livestock (Graziani et al., 2015) and it has never been recovered from foodstuffs of animal origin in southern Italy (Proroga et al., 2015), whereas its detection in several wild animals has been reported in Italy (wild boars Chiari et al., 2013; Zottola et al., 2013; wild birds Mancini et al,. 2014).

\section{Antibiotic resistance}

Twenty-six $\%$ of the isolates were susceptible to all the antibiotics tested. Among the top four serotypes analysed, $S$. Enteritidis (77.5\%) and S. Napoli (57.2\%) showed the lowest drug resistance, while $S$.
Table 2. Antibiotic resistance profiles in 150 Salmonella strains of human origin.

\begin{tabular}{|c|c|}
\hline Prevalence, \% & Resistance profiles \\
\hline 26.0 & Pan susceptible \\
\hline 25.3 & A- S- Su- T \\
\hline 10.0 & A- S- Su- T- Na \\
\hline 2.6 & A- C-S-Su-T-Amc \\
\hline 2.6 & $\mathrm{~T}$ \\
\hline 2.0 & $\mathrm{Na}$ \\
\hline 1.3 & S- Su- T- Na- Stx \\
\hline 1.3 & A- S- Su- T- Cf- Na \\
\hline 1.3 & S- Su- T \\
\hline 1.3 & A- S- Su- T- Amc \\
\hline 1.3 & S \\
\hline 0.6 & $\mathrm{Cf}$ \\
\hline 0.6 & Amc-K \\
\hline 0.6 & A \\
\hline 0.6 & T- Cip \\
\hline 0.6 & A- C-S-Amc- Cf \\
\hline 0.6 & A- C- S- Cf \\
\hline 0.6 & A- C-S-Su- T \\
\hline 0.6 & A- S- Su- T- Na- K-Stx \\
\hline 0.6 & A-S-Su- T- Na-Stx \\
\hline 0.6 & A- S- T- Amc- Cf- Na \\
\hline 0.6 & A- C- S- Su- T- Cf- Na \\
\hline 0.6 & A- S- Su- T- K \\
\hline 0.6 & A- C-S-Su- T- K- Stx \\
\hline 0.6 & A- C- S- Su- T- Stx \\
\hline 0.6 & A- S-Su- T-Stx \\
\hline 0.6 & A- S- Su-Amc \\
\hline 0.6 & A- C- S- Su- T- Amc- K \\
\hline 0.6 & A- S- Su- T- Ctx- Caz- Na \\
\hline 0.6 & C- S- Su- T \\
\hline 0.6 & C-S- T \\
\hline 0.6 & A- Su- T- Caz \\
\hline 0.6 & A- C- S- Su- T- Amc- Cu K-Stx \\
\hline 0.6 & A- C- S- Amc- Na- Cip- Enr- Cu K \\
\hline 0.6 & A- C- S- Su- T- Cf- $K$ \\
\hline 0.6 & A- S- Su- T- Cf- Enr- K- Stx \\
\hline 0.6 & A- S- Su- T- Amc- Cf- Stx \\
\hline 0.6 & A- C- S- Su- T- Cf- Na- Enr- Stx- Cl \\
\hline 0.6 & S- T- Na \\
\hline 0.6 & S- T- Na- Enr \\
\hline 0.6 & S- T- Cf- Na- K- Cl \\
\hline 0.6 & $\mathrm{~S}-\mathrm{Su}$ \\
\hline 0.6 & T- Cip \\
\hline 0.6 & $\mathrm{Su}-\mathrm{T}$ \\
\hline 0.6 & $\mathrm{C}-\mathrm{Na}$ \\
\hline 0.6 & $\mathrm{C}-\mathrm{T}-\mathrm{Na}$ \\
\hline 0.6 & $\mathrm{C}-\mathrm{T}$ \\
\hline 0.6 & $\mathrm{Cu}$ \\
\hline
\end{tabular}

A: Ampicillin; Amc: Amoxicillin-clavulanic acid; C: Chloramphenicol; Caz: Ceftazidime; Cip: Ciprofloxacine; Cl: Colistin sulphate; $\mathrm{Cn}$ Gentamicin; Ctx: Cephotaxime; Enr: Enrofloxacin; K: Kanamycin; Kf: Cephalothin; Na: Nalidixic acid; S: Streptomycin; Su: Sulphonamide; Sxt: Trimethoprim-sulphametoxazole; T: Tetracycline. 
Typhimurium and S. 4,[5],12:i:- displayed this study. the highest number of resistances.

The resistance to the critically important antibiotics for human therapy, cefotaxime and ciprofloxacin, was very low, $0.6 \%$ and $1.3 \%$, respectively; and none of the strains tested showed co-resistance to ciprofloxacin and cefotaxime. Furthermore frequent resistance to nalidixic acid was observed $(23.3 \%)$, especially among $S$. Typhimurium strains $(46.9 \%)$. In $S$. Typhimurium isolates, the R-type ASSuT was frequently $(81 \%)$ associated to resistance to other antibiotics: nalidixic acid (51.3\%), chloramphenicol (27\%), trimethoprim-sulphametoxazole $(21.6 \%)$, amoxicillin-clavulanic acid (18.9\%), cephalothin (13.5\%), kanamycin (10.8\%), enrofloxacin $(8.1 \%)$, cephotaxime, ceftazidime, ciprofloxacin, gentamicin, colistin sulphate (2.7\%). In $S .4$, [5],12:i:- additional resistances to ASSUT R-type were rare (16.2\%): 3 to nalidixic acid, 2 to amoxicillin-clavulanic acid, 1 to chloramphenicol, cephalothin and kanamicin, respectively. The R-type ASSuT associated with the resistance to chloramphenicol (R-type ACSSuT), which had a considerable impact on human health in the past, recently appears to be less frequent than R-type ASSuT with additional resistance to nalidixic acid (R-type ANaSSuT). ANaSSuT, in fact, is one of the most common R-types among the isolates analyzed in
According to our data, the likelihood of recovering the ASSuT Salmonella R-type in human salmonellosis in the considered areas is significantly higher than nonASSuT strains $\left(X^{2}=88.6\right)$.

In relation to virulotyping, as expected, the gene invA was detected in all the samples, irrespective of serotype.

None of the plasmid gene showed a prevalence higher than $34 \%$. In agreement with the findings of Huehn et al. (2010) and Graziani et al. (2011), we did not find virulence plasmid genes in all $S$. Napoli and $S$. 4,5,12:i- isolates.

As reported by Rotger and Casadesús (1999), virulence plasmids were found only in a few serotypes of Salmonella (Table 3); although these two authors reported that all virulence plasmids share the $s p v$ gene, in our study the presence of plasmids related genes was not always associated to the presence of the $s p v C$ gene. This could mean that Salmonella can harbour more than one virulence plasmid. Genes related to bacterial virulence of phage origin ( $\operatorname{tip} A, \operatorname{gtg} B$, nanH, grvA, sopE, sspH1, sspH2 and $\operatorname{sod}(1)$ were unevenly detected among the tested serotypes. Among the four serotypes of more common detection, none of the phagic genes was missing in $S$. Typhimurium isolates, while 3 genetic elements (nanH, grvA, and $g \operatorname{tg} E$ ) were never detected in $S$. Enteritidis and $S$. 4,[5],12:i:-.
$S$. Napoli was the serotype with the lowest number of loci; indeed, only four out of the eight considered phagic genes were recovered from this serotype (Table 3 ).

A similar prevalence of $\operatorname{gtg} B(127 / 150)$ and $\operatorname{sspH} 2(130 / 150)$ was detected in all isolates, while nanH (1/150) and $\operatorname{gtg} E$ $(1 / 150)$ were found only in $S$. Typhimurium strains. sodC1 (116/150) was detected in all most common serotypes, except $S$. Napoli.

Overall, 49 different virulence patterns were observed, 33 of which concerned the top 4 serovars. $S$. Typhimurium was the serotype that showed the greatest number of profiles for the virulence genes considered. It is noteworthy that the prevalent virulotype was identical in $S$. 4,[5],12:1:- and $S$. Typhimurium isolates (Table 4).

$S$. Typhimurium, $S$. Enteritidis and $S$. 4,[5],12:i:- showed marked homologies in virulotypes and drug resistance profiles, though $S$. Typhimurium displayed greater variability.

\section{Phage markers}

None of the Salmonella isolates analysed were positive for the presence of all these markers; in particular, 92, 28 and 8 isolates harboured 1,2 and 3 markers, respectively. Twenty-two strains were devoid of phage markers. Isolates showed different positivity rates to the phage markers considered $(g 8,80.0 \%$; sieB, $17.3 \%$; g13 12.0\%; eaC, 5.3\%). Serotype $S$. Napoli

Table 3. Detection of virulence gene in Salmonella strains of human origin.

\begin{tabular}{|c|c|c|c|c|c|c|c|c|c|c|c|c|c|c|c|c|c|c|c|}
\hline $\begin{array}{l}\text { Salmonella strain } \\
\text { Serotype }\end{array}$ & No. & invA & $\begin{array}{l}\text { Phage } \\
\text { g13 }\end{array}$ & $\begin{array}{l}\text { mark } \\
\text { sieB }\end{array}$ & $e a C$ & g8 & gipA & $\operatorname{gtg} B$ & $\begin{array}{l}\text { irulenc } \\
\text { nanH }\end{array}$ & $\begin{array}{l}\text { e ger } \\
\text { groA }\end{array}$ & $\begin{array}{l}\text { e of p } \\
\text { sopE }\end{array}$ & $\begin{array}{l}\text { hage or } \\
\text { sspH1 }\end{array}$ & igin & $\operatorname{sodC1}$ & $\begin{array}{l}\text { Plası } \\
s p v C\end{array}$ & $\begin{array}{l}\text { nidic } \\
\text { peff }\end{array}$ & $\begin{array}{l}\text { virule } \\
\text { mig5 }\end{array}$ & $\begin{array}{l}\text { rce g } \\
\text { rck }\end{array}$ & $\begin{array}{l}\text { enes } \\
\operatorname{srg} A\end{array}$ \\
\hline Typhimurium & 49 & 49 & 6 & 17 & 7 & 47 & 41 & 46 & 1 & 4 & 11 & 36 & 46 & 43 & 5 & 4 & 8 & 8 & 13 \\
\hline Enteritidis & 40 & 40 & 2 & 1 & - & 29 & 8 & 37 & - & - & 37 & 2 & 37 & 38 & 2 & 30 & 37 & 38 & 37 \\
\hline 4,[5],12:i:- & 37 & 37 & - & 1 & 1 & 33 & 37 & 36 & - & - & 14 & 28 & 33 & 33 & - & - & - & - & - \\
\hline Napoli & 7 & 7 & 6 & 1 & - & - & 1 & 7 & - & - & 6 & 6 & 7 & - & - & - & - & - & - \\
\hline Derby & 2 & 2 & 1 & 1 & - & 2 & - & - & - & - & - & - & - & - & - & - & - & - & - \\
\hline Poona & 2 & 2 & 1 & 1 & - & 1 & - & - & - & - & 1 & - & 1 & - & - & - & - & - & 1 \\
\hline Rissen & 2 & 2 & - & 2 & - & 2 & - & - & - & - & - & - & 1 & - & - & - & - & - & - \\
\hline Agama & 1 & 1 & 1 & 1 & - & 1 & 1 & - & - & - & - & - & 1 & - & - & - & - & - & - \\
\hline Blockley & 1 & 1 & - & - & - & - & 1 & 1 & - & - & - & 1 & 1 & 1 & - & - & - & - & - \\
\hline Brandenburg & 1 & 1 & - & - & - & 1 & - & - & - & - & - & 1 & - & - & - & - & - & - & - \\
\hline Bredeney & 1 & 1 & - & - & - & 1 & - & - & - & - & - & 1 & 1 & - & - & - & - & - & - \\
\hline Edinburgh & 1 & 1 & - & - & - & - & - & - & - & - & - & - & - & - & - & - & - & - & - \\
\hline Hadar & 1 & 1 & - & - & - & 1 & 1 & - & - & - & - & 1 & 1 & - & - & - & - & - & - \\
\hline Irumu & 1 & 1 & 1 & - & - & 1 & - & - & - & - & - & - & - & 1 & - & - & - & - & - \\
\hline Manhattan & 1 & 1 & - & - & - & - & - & - & - & - & - & 1 & - & - & - & - & - & - & - \\
\hline Muenster & 1 & 1 & - & - & - & - & - & - & - & - & - & - & - & - & - & - & - & - & - \\
\hline Nyborg & 1 & 1 & - & - & - & - & - & - & - & - & - & 1 & - & - & - & - & - & - & - \\
\hline Ohio & 1 & 1 & - & 1 & - & 1 & - & - & - & - & - & 1 & 1 & - & - & - & - & - & - \\
\hline All serotypes & 150 & 150 & 18 & 26 & 8 & 120 & 90 & 127 & 1 & 4 & 69 & 79 & 130 & 116 & 7 & 34 & 45 & 46 & 51 \\
\hline
\end{tabular}


was found often positive (5/6) for $g 13$. These 4 loci were associated in different ways, allowing the identification of 13 different profiles.

A strain of $S$. Typhimurium was characterized by the presence of the largest number of genes investigated (invA; gipA; $\operatorname{gtg} B$; grvA; sspH1; sspH2; sodC1; spvC; pefA; mig5; $r c K ; \operatorname{srg} A$ ). Overall only in $S$. Typhimurium isolates all investigated genes were detected; indeed the Salmonella serotypes Enteritidis, 4,[5],12:i:- and Napoli were positive for invA and 14, 9 and 7, respectively, of all the loci analysed (Table 3).

\section{Conclusions}

Although other and highly discriminating assays are today available, the use of these techniques provide useful information in studying the patterns of Salmonella infections. While many assays have been well standardized over the years (e.g. serotyping and antibiotic resistance), the detection of specific virulence and phage marker genes need further studies to make this technique fully comparable among different laboratories. Nonetheless, Salmonella virulotype recognition is a useful and promising approach for drawing up a panel of genes to use in epidemiological surveys and the combination of phenotypic and molecular assays has proved to be useful tools combination for epidemiological characterization of Salmonella isolates. The S. 4,[5],12:i:- serotype is usually reported as characterized by a single phenotypical profile; by contrast, in our study we identified 12 different profiles of this serotype. The increasing relevance of $S$. Napoli in Italy led to support its inclusion in the panel of strains to be considered in epidemiological studies.

The preliminary data from this study have considerable epidemiological implications. The combination of phenotypic and molecular assays for the characterization of Salmonella isolates proved to be helpful and relatively easy to implement.

\section{References}

Abatcha MG, Zakaria Z, Goni DM, Kaur DG, 2014. Typing of Salmonella Species: A Mini-Review. J Nat Sci Res 4:13-7.

Borriello G, De Carlo E, Iovane G, Capuano F, 2010. Genetic characterization of Salmonella strains isolated from water buffalo calves with diarrhea. Rev Vet 21:190.
Capuano F, Mancusi A, Capparelli R, Esposito S, Proroga YTR, 2013. Characterization of Drug Resistance and Virulotypes of Salmonella Strains Isolated from Food and Humans. Foodborne Pathog Dis 10:963-8.

Chiari M, Zanoni M, Tagliabue S, Lavazza A, Alborali LG, 2013. Salmonella serotypes in wild boars (Sus scrofa) hunted in northern Italy. Acta Vet Scand 55:42.

Chiu CH, Ou JT, 1996. Rapid identification of Salmonella serovars in feces by specific detection of virulence genes, invA and spvC, by an enrichment broth culture-multiplex PCR combination assay. J Clin Microbiol 34:2619-22.

Clinical Laboratory Standards Institute (CLSI). Performance standards for antimicrobial susceptibility testing, $9^{\text {th }}$ informational supplement. CLSI, Wayne, Pennsylvania 2008.

Dauga C, Zabrovskaia A, Grimont PA, 1998. Restriction fragment length polymorphism analysis of some flagellin genes of Salmonella enterica. J Clin Microbiol 36:2835-43

Drahovska H, Mikasova E, Szemes T, Ficek A, Sasik M, Majtan V, Turna J, 2007. Variability in occurrence of multiple prophage genes in Salmonella Typhimurium strains isolated in the Slovak Republic. FEMS Microbiol Lett 270:237-44.

European Food Safety Authority, European Centre for Disease Prevention and Control, 2015. The European Union Summary Report on Trends and Sources of Zoonoses, Zoonotic Agents and Food-borne Outbreaks in 2014. EFSA Journal 13:4329.

Graziani C, Arigoni F, Turno P, Macchioni D, Pileggi C, Pavia M, Veltri P, Casalinuovo F, Capuano F, Sarnelli P, Luzzi I, Busani L, 2015. Valutazione del rischio sanitario di infezioni da agenti zoonosici attraverso prodotti vegetali ottenuti in aree ad elevata pressione zootecnica. Roma: Istituto Superiore di Sanità. (Rapporti ISTISAN 15/33) http://www.iss.it/binary/publ/cont/15 3 3 web.pdf

Graziani C, Busani L, Dionisi AM, Caprioli A, Ivarsson S, Hedenström I, Luzzi I, 2011. Virulotyping of Salmonella enterica serovar Napoli strains isolated in Italy from human and nonhuman sources. Foodborne Pathog Dis 8:9971003.

Graziani C, Mughini-Gras L, Owczarek S, Dionisi AM, Luzzi I, Busani L, 2013. Distribution of Salmonella enterica isolates from human cases in Italy, 1980 to 2011. Euro Surveill 18:20519.
Grimont PA, Weill FX. Antigenic formulae of the Salmonella serovars. 9th Edition. Paris, France: WHO Collaborating Centre for Reference and Research on Salmonella.

2007. http://www.scacm.org/free/Antigenic $\%$ 20Formulae $\% 20$ of $\% 20$ the $\% 20$ Salmone 1la\%20Serovars\%202007\%209th\%20e dition.pdf (Accessed December 10, 2015)

Havelaar AH, Ivarsson S, Lofdahl M, Nauta MJ, 2012. Estimating the true incidence of campylobacteriosis and salmonellosis in the European Union, Epidemiol Infect 141:293-302.

Heithoff DM, Shimp WR, Lau PW, Badie G, Enioutina EY, Daynes RA, Byrne BA, House JK, Mahan MJ, 2008. Human Salmonella clinical isolates distinct from those of animal origin. Appl Environ Microbiol 74:1757-66.

Ho TD, Slauch JM, 2001. Characterization of grvA, an antivirulence gene on the gifsy-2 phage in Salmonella enterica serovar typhimurium. J Bacteriol Jan 183:611-20.

Huehn S, La Ragione RM, Anjum M, Saunders M, Woodward MJ, Bunge C, Helmuth R, Hauser E, Guerra B, Beutlich J, Brisabois A, Peters T, Svensson L, Madajczak G, Litrup E, Imre A, Herrera-Leon S, Mevius D, Newell DG, Malorny B., 2010. Virulotyping and antimicrobial resistance typing of Salmonella enterica serovars relevant to human health in Europe. Foodborne Pathog Dis 7:52335.

Lucarelli C, Dionisi AM, Torpdahl M, Villa L, Graziani C, Hopkins K, Threlfall J, Caprioli A, Luzzi I, 2010. Evidence for a second genomic island conferring multidrug resistance in a clonal group of strains of Salmonella enterica serovar Typhimurium and its monophasic variant circulating in Italy, Denmark, and the United Kingdom. J Clin Microbiol 48:2103-9.

Magiorakos AP, Srinivasan A, Carey RB, Carmeli Y, Falagas ME, Giske CG, Harbarth S, Hindler JF, Kahlmeter G, Olsson-Liljequist B, Paterson DL, Rice LB, Stelling J, Struelens MJ, Vatopoulos A, Weber JT, Monnet DL, 2012. Multidrug-resistant, extensively drug-resistant and pandrug-resistant bacteria: an international expert proposal for interim standard definitions for acquired resistance. Clin Microbiol Infect 18:268-81.

Mancini L, Marcheggiani S, D’Angelo A, Puccinelli C, Chiudioni F, Rossi F, Delibato E, De Medici D, Dionisi AM, Luzzi I, 2014. First isolation of 
Salmonella enterica serovar Napoli from wild birds in Italy. Ann Ist Sup Sanità 2014;50:96-8.

Mellou K, Sideroglou T, Kallimani A, Potamiti-Komi M, Pervanidou D, Lillakou E, Georgakopoulou T, Mandilara G, Lambiri M, Vatopoulos A, Hadjichristodoulou C, 2013. Evaluation of underreporting of salmonellosis and shigellosis hospitalized cases in Greecie, 2011: results of a capturerecapture study and a hospital registry review. BMC Public Health 13:875.

Mikasovà E, Drahovska H, Szemes T, Kuchta T, Karpiskova R, Sasik M, Turna J, 2005. Characterization of Salmonella enterica serovar Typhimurium strains of veterinary origin by molecular typing methods. Vet Microbiol 109:113-20.

Pires S, de Knegt L, Hald T, 2011.
Scientific/technical report submitted to EFSA - Estimation of the relative contribution of different food and animal sources to human Salmonella infections in the European Union, Question No EFSA-Q-2010-00685. Parma: European Food Safety Agency. Available from: http://www.efsa.europa.eu/en/supporting/doc/184e.pdf (Accessed December 19, 2015)

Popoff MY, Le Minor LE, 2005. Genus XXXIII. Salmonella. In Brenner DJ, Krieg NR, Stanley JT (Eds) Bergey's Manual of Systematic Bacteriology. Vol 2. 2nd ed. Springer, New York, pp 764799.

Proroga YT, Capuano F, Carullo MR, La Tela I, Capparelli R, Barco L, Pasquale $\mathrm{V}, 2015$. Occurrence and antimicrobial resistance of Salmonella strains from food of animal origin in southern Italy. Folia Microbiol 61:21-7.

Rotger R, Casadesùs J, 1999. The virulence plasmids of Salmonella. Int Microbiol 177-84.

Wattiau P, Boland C, Bertrand S, 2011. Methodologies for Salmonella enterica subsp. enterica Subtyping: Gold Standards and Alternatives: gold standards and alternatives. Appl Environ Microbiol 77:7877-85.

Zottola T, Montagnaro S, Magnapera C, Sasso S, De Martino L, Bagagnolo A, D'Amici L, Condoleo R, Pisanelli G, Iovane G, Pagnini U, 2013. Prevalence and antimicrobial susceptibility of Salmonella in European wild boar (Sus scrofa); Latium Region - Italy. Comp Immunol Microbiol Dis 36:161-8. 